\title{
Informal Methods of Social Control in Society, Their Types and Their Effectiveness in Reducing Crime
}

\author{
Abdulrahman Khaled Al ibrahimy \\ Phd Social Sciences, Faculty of Social Sciences, University of Algiers 2 - Abou EL Kacem \\ Saâdallah, Algeria \\ Email: $\underline{\text { Abdkh251@yahoo.fr }}$
}

\begin{abstract}
:
The means and methods of social control are the tools used and used in maintaining the stability, stability, permanence, progression, progress, and development of the social system and society more fully, and the social system is exposed to many dangers and challenges that it faces, which result from defects and bad relationships. And human dealings, disruption of social behavior, and the transformation of structural institutions is a heterogeneous transformation that negatively affects the march of society, and the dangers and challenges that threaten the security and safety of society transcend themselves in unbridled and unbridled practices and actions, deviant actions, trends, and twisted currents. And the wire is straightforward that deviates from the correct behavioral and interactive context, which is recognized and recognized by society, accepted and tolerated by customs and traditions, and in our research, we will present informal methods of social control in society and we will learn about their effectiveness in reducing crime.
\end{abstract}

Keywords: Society, Crime, Methods, Social Control 


\section{Introduction}

The concept of social control is a major topic in the heritage of the social sciences, especially sociology, as the individual by nature is a social creature who cannot survive alone, and must end with a society from which he derives strength and protection. This party and its founders maintain relations with each other and cooperate in protecting themselves and achieving their goals. Hence, the collective need to regulate their actions and control the various behaviors that they carry out to organize their lives emerged, and societies focus on the moral principles that members of society believe in and represent the goals and objectives that they undertake. We strive to achieve them, and the group's values are transferred to its activities. And their behavior and they consider those who violate it as a punishment for them from here, special laws have emerged to regulate incentives to meet simple needs, these principles will soon become a basis for creating society, and in some cultures, they will become such as laws, constitutions and written laws. Social management is an ancient concept that comes from the basic premise that every social life takes place by nature on an organization and that every organization requires some kind of control. Social control is an ancient mechanism known to mankind and known to man since ancient times, and certain techniques have been used to make it possible to coordinate social interactions, and given the importance of social control to human society, social control has been developed by nature of this society as a condition for organizing its affairs. Ibn Khaldun added to this in his famous introduction, where he said: "When a meeting is held for human beings, there must be caution in pushing each other on behalf of each other because of their animal behavior in violence and injustice. So that no one attacks another with violence, and this is the king's sense. "The increased attention to the issue of social discipline, especially in light of the spread of the epidemic of perversion and criminality in society, so that the illegal behavior is that anti-social behavior, and violates the laws and customs of that society so that the victim is punished for two reasons. One is to dissuade the aggressor. The other is to protect people from affected and criminal behavior. Rather, it is a big problem in every culture because, regardless of the rest of society and its members, it poses an explicit challenge to social order and social values, and this activity is well known, especially in all emerging urban areas. Crime in its various forms is not only seen as a result of the rapid development of society, but is also linked as a tendency to work with rapid and successive transformations in different ways of life, 
Such as the role of parents, work, inadequate educational curricula, prevailing cultural influences, and hence the urgent need for regulation. Social and its importance in its sustainability.

\section{Research questions}

What is social control?

- What are the informal means of social control in society?

- How effective is informal social control in reducing crime?

\section{The importance of studying:}

The issue of social organization has received great attention from sociologists since Ibn Khaldun decided that social control is the basis of social life and the preservation of its security and the continuation of its existence. The American scientist Edward Ross, who emphasized the importance of regulation, expanded his interest in the topic of social control. Social life in social life and the preservation of the entity of society, then the censorship thesis developed in the recent period with the increase in research conducted on the chapters and mechanisms of social communication, and the focus on new topics in sociology, such as levels of social interference, social norms, beliefs and general rules of behavior. The importance of the social impact of human civilization, the nature of this society has been determined. Crime and deviant behavior are among the social challenges that human civilization faced in all its eras, combinations, and various types. The focus of attention of social thinkers such as reformers, clerics, philosophers, and others, and from here every work to study according to his specialization, especially in light of the wide wave of deviation and crime that the world has witnessed in recent times, which social, economic and technological change has led to, in every place where it happened. Modern and new patterns of criminality and delinquency, which have become increasingly widespread in many societies. From this point of view, the significance of this analysis tends to be a discussion of its topic.

\section{Research aims:}

- Learn about social control

- Knowledge of informal methods of social control in society 
- Show the types of informal social control

- Determining the effectiveness of social control in reducing crime

\section{Previous studies:}

On the one hand, the study of seizure and its role in curbing criminal activity is one of the studies that received great interest from social scientists. Studies and studies on delinquent behavior and criminality began in the forties of the last century and did not stop to some extent, and interest in this aspect increased. Especially in the face of the high crime rate and deviant behavior in many cultures, and from this point of view, studies have been conducted, some of which can be listed:

1- A thesis by Dr. Salah Hassan Ahmad Al-Ezzi entitled "The role of socialization in curbing criminal behavior," a field study in the city of "Kirkuk." This research aimed to determine the effects of criminal activity, whether on the individual or society as a whole and to explain the role that socialization plays in curbing Crime, which is a social issue.

2- Khalifa Ibrahim Odeh Al-Tamimi examines the reality of violence in the countryside. It is a field study in which the researcher used conversation, questionnaires, and basic observation based on the social survey process. This analysis aimed to describe the reality of the crime in the countryside of Diyala Governorate, Iraq, as a representative of the Iraqi rural population in terms of crimes, their characteristics, and the characteristics of their perpetrators. In addition to determining the relationship between the social, cultural, and economic reality of the countryside in Diyala Governorate, Iraq, and the facts of the crime, the researcher tried to verify the ability of social forces to push individuals to erase criminal activity. And the participants entered the survey, and the researcher concluded that there is a strong relationship between the need for a scenario and the nature of the crime and that most of the crimes committed in the countryside are open. Daily and in the public sphere, as well as from the report findings, rural social values play a role in promoting illegal activity and social traditions are the most common form of social influence in the rural community.

Search terms

The concept of social control: 
* The subject of social control suffers from a great deal of uncertainty and misunderstanding, largely due to the differences among the scholars themselves regarding their understanding of the concept of social control and their dissatisfaction with the simple definition of it as well. In terms of their disagreement with the field of social control and its flaws as a mechanism that has many consequences. And ideas that contradict the description of their dimensions and functions by looking at their metaphysical and experimental foundations and areas.

* References to the issue of order and laws governing behavior and authority were included in many ancient texts. Ancient Greek thinkers dealt with the question of social discipline but used other terms such as law, philosophy, tradition, or ethics. However, the first pioneer of the idea of social control is the Arab scientist Ibn Khaldun, who commented in his presentation more clearly and precisely on social control by saying: "A human meeting is required and in the meeting of the king, his appeal and judgment over them is necessary, either based on God's law, he must be guided to him by their belief in the reward. Punishment, and a reasonable strategy that allows them to approach him with what they expect from compensating that king, after knowing their interests.

It is also believed that a person needs supervisory authority for his social actions and that urban planning needs the participation of stakeholders and authority to have successful motives and protect the facilities. The means of control that achieve this goal are expressed in religion, law, laws, customs, and traditions. ${ }^{1 "}$

- The principle of the social organization refers to the set of principles and rules that exist in a society in which tensions and conflicts can be organized between individuals to help them achieve harmony and communication between individuals and societies.

\section{Literature review:}

\section{Definition of social control:}

${ }^{1}$ Al-Khatib Muhammad Al-Shahat and others, The Fundamentals of Islamic Education, Dar Al-Kharji for Publishing and Distribution, 1959, p. 530 
* "It is a social challenge, that is, the people's attempt to reach and achieve those goals, and to meet basic human needs."

* Social organization, in its general context, is the mechanisms and intentional and accidental actions taken by society to organize the activities of people within that community and act according to the standards, principles, or structures that have been developed for them. Social influence in contemporary society is related to public opinion and government through legislation, whereas in traditional cultures, social patterns such as customs and traditions play a vital role in social organization.

\section{Sociologists' definitions of social control:}

* George Gurevich knows him: "It is a set of cultural paradigms, group images, mutual moral meanings, beliefs, ideas and principles as well as behavior and processes associated with them specifically through which culture, society, and every person can remove tension and distress within them through a timer of balance and take steps towards Creative activities with successful outcomes.

- Charles Zaconi defines it as "the self-control of society that is achieved through the mechanism of organization and backwardness and not through people or individuals."

Paul Landes defines it as a set of social processes that make individuals responsible for society and the creation and maintenance of the social organization. Through it, the identity of the individual is shaped by his social normalization and contributes to the realization of a more complete social structure for his mother. It is not possible to develop an organized society or build an embodied identity without a set of binding principles.

- And "Joseph Rusk" defines it: social control as "a general term related to the mechanisms by which these principles and procedures are taught, manipulated,

or required to be followed, by people, whether these operations are carried out in conjunction with a determined and deliberate relationship or are executed automatically."

${ }^{2}$ Ibrahim Abu Al-Far, Legal Sociology and Social Control, Cairo Al Sharq Library, 1958, p. 215 


\section{Second: Informal means of social control:}

\section{1- Social Habits:}

* The behavioral standards imposed by society on its members differ from one society to another, according to a series of standards that society has traditionally used to meet people's needs and coordinate social ties between them. "These controls are automated at their inception and are restricted by their basic dimensions, steps, and procedures. They have a direct effect, and the greater the number of categories and the complexity of their construction and functions, the more complex the means of controlling them."

They are not receiving the care and attention they need, given the value of informal (automatic) methods of control, especially those that rely on violence and force. Public morality, as it is derived from the social order, wherein its governing role performs the duties of social organization that function as a codified (or formal) authority in industrial societies. Social habits can be described as a type of social behavior that persisted for a long time and settled in a particular society and became the standard patterns of thinking and action associated with the sub-group or society as a whole.

As a society without unimaginable social habits, these habits are a social duty to govern individuals' transactions and manage their relationships. These customs contain permissible and impermissible legal orders, restrictions and duties, respectful, inappropriate, beneficial, and abhorrent, that is, they benefit from selfish interests, discourage violent tendencies, and limit reckless behavior. The basis of social interaction is some social limitations and controls that have a personal purpose, so they simply explain social interactions and provide the community with guidelines for interacting with its members and what these standards include, depending on The group experience. For this purpose, social traditions and the basic roles they provide in managing and organizing society are among the most effective and important means for community unity and preserving its life, continuity, and dignity.

\section{2 - Customs and traditions:}

* One of the basic factors in the mechanism of social organization is that every human society has a set of rules, and its peculiarities are culture, which means " the application or social 
activity that a person learns as a social habit, and it is followed by all members of society as part of the rituals, which are placed on them from During the exclusion of everyone by society. "

Based on the relationship between customs and practices referred to above, on the basis that customs are part of the traditions, as traditions are often seen as unwritten laws. Breaking it leads to responses that vary in size and severity according to the extent and method of the violation, and which deviate from the principles and determinants of some customs and norms that do not have the status of official duty but have the power of social influence, which makes most members of society unable to change it for fear of disapproval or contempt. Especially in conservative or traditional cultures, where rituals and practices are regulated by the rule of law in their hearts.

\section{3- Traditions}

The definition:

* Tradition is the oldest source that aims to repeat the actions of people in a matter related in some way to the assumption that this behavior is morally binding on them and that tradition consists of two elements: A material component: reproducing people's behavior

The religious element is the conviction of people that this habit is legally binding. Customs is a category of cultural habits that parallels traditions in the sense that they are traditional, normative, hereditary, and binding, except that they differ from them in the degree to which they are binding, common, comprehensive, and general. It is one of the widespread customs in its distribution, which is not in the interest of a special group alone, but rather in the interest of all groups that meet in one group, that is, society or the country.

The scholar "Al-Jarjani" described tradition in his book "Al-Tarifa". Tradition in the language is what the testimony of minds has settled upon, and nature has accepted it.

Abd al-Karim Zidan explains it as "what society has become accustomed to and used to and followed in his life by saying or deed.

The custom does not deviate from being a practical tool through which the group allows its influence and control over the entity to maintain its unity and dynamism at the same time, and for this reason, the habit loses its sense if the emptiness takes place. 
Within it without organizing the organization and development of social and social structures. Man's attempts to achieve these unique purposes are linked to his fundamental interests, and he also signifies the social classes and systems upon which he was brought up.

No society can live and continue without a social connection that binds people and allows them to meet their basic and secondary needs, which is not spontaneous and unorganized, but there are restrictions on social behavior, which we mean by the language of social structures. It carries out its tasks while continuing to work. In this regard, according to Rad Cliff Brown, social structures are stereotypical methods of social action and the apparatus through which a social system can be stabilized and maintained. It occurs in the context of social interaction and is therefore a group of No society can live and continue without a social connection that binds people and allows them to meet their basic and secondary needs, which is not spontaneous and unorganized, but there are restrictions on social behavior, which we mean by the language of social structures. It carries out its tasks while continuing to work. In this regard, according to Rad Cliff Brown, social structures are stereotypical methods of social action and the apparatus through which a social system can be stabilized and maintained. It occurs in the context of social interaction and is thus a set of social norms prevailing in society, which consists of rituals, practices, and values arranged with or without consciousness.

\section{The effectiveness of informal social control in reducing crime}

Informal social influence, defined by social norms, traditions, customs, and traditions, plays an important role in reducing crime. But often it is not enough to reduce the violence. In some cultures, some crimes are based on custom. Thus without formal social regulations, it is not necessary for the rule of society, even though its laws are the most reliable representation of what the members of society agree upon in arranging their relationships so that they are acceptable under their establishment of social conditions. Often the same approach in drafting customary laws contributes to their development as conditions in society change and remain appropriate to them.

However, its disadvantage is that it is gradually created and lacks consistency and creativity, and it may be difficult to prove the existence of regulation or validate its essence, which negates continuity and confidentiality in transactions. 
Often customs are more localized and thus contribute to the multiplicity of structures in one country that disintegrates its unity and impedes its development, just as the custom is a desire to preserve values, including the love of rituals and concern for the familiar, so that it is not something to get rid of. However, it does not provide an opportunity to present new proposals that reformists see as beneficial to society long before.

\section{Conclusion}

Formal and implicit forms of social organization, such as religion, legislation, culture, practices, and customs, perpetuate the social structure with deterrence, punishment, and compliance with the law. What is the relationship of faith with social harmony and achieving group unity? Some see it as the duty of formal and informal means of social organization for the rise of criminality and deviation in society. Where many experiments and empirical studies have found that there is an interactive relationship between the means of social organization and the phenomenon of crime and delinquency, as crime rates increase in society, whether the society is rural, urban, basic, or complex, where there are no effective measures of social control, and the rates are declining. Society crimes in which the means of social organization are present and successful and have a distinct role to play in preventing people from engaging in unruly and deviant behavior. This is because the presence of means of social influence in the cultural arena is seen as a barrier to the person requesting illegal activity. In addition, formal and indirect forms of social discipline restore consideration to society as it is vulnerable to violence by imposing penalties or punishment on individuals who commit crimes and crimes against society.

Consequently, individuals look to commit crimes against society for fear of using social control methods as tools to deter and besiege crime and delinquency, but the leniency and weakness of the means of social control and their failure to control situations and relationships and the communications of individuals and societies increase the volume of violations and the sins of humanity.

\section{Recommendations and suggestions}

1- Paying attention to informal means of social control and trying to discuss and codify them in state law 
2- It is not possible to rely on informal means only, as the customs and traditions differ from one site to another

3- The role of law and religion must be activated to control norms and traditions.

\section{References}

1. Al-Khatib Muhammad Al-Shahat and others, Fundamentals of Islamic Education, Dar AlKharji for Publishing and Distribution, 1959

2. Ibrahim Abu Al-Far, Legal Sociology and Social Control, Cairo, Al Sharq Library, 1958

3. Samir Naim Ahmed, Legal Sociology, Cairo, Dar Al Maarif, 2nd Edition, 1982

4. Musleh Al-Saleh, Social Control, Amman, Al-Warraq Foundation for Publishing and Distribution 1st Edition, 2004

5. Muhammad Atef Ghaith, Sociology, Alexandria University Knowledge House, 1987

6. Fawzia Diab, Values and Knowledge, Cairo Arab Book House for Printing and Publishing

7. Muhammad al-Taqiya, Sources of Islamic Legislation, The National Office

8. Abdel-Karim Zidan, Al-Wajeez fi Usool al-Fiqh, Cairo, Arab Renaissance House

9. Muhammad Ahmad Bayoumi, Sociology between Islamic Awareness and Expatriate Consciousness, University Knowledge House, 1993

10. Rad Cliff Brown, Functional constructivism in primitive societies, London, 1952

11. Sabaie Souad, The Role of Social Control in Reducing Criminal Behavior in Algerian Society, Field Study of a Sample of Deviant Youth in Mostaganem City, Graduation Memorandum to Obtain a Master's Degree in Educational Sociology, Faculty of Social Sciences, Abdel Hamid Ibn Addis University - Mostaganem, Algeria, 20132014

Copyright (C) 2021 Abdulrahman Khaled Al ibrahimy, AJRSP. This is an open-access article distributed under the terms of the Creative Commons Attribution License (CC BY NC).

DOI: doi.org/10.52132/Ajrsp.e.2021.253 